\title{
Projecting the population size of Dhaka city with migration using growth rate method
}

\author{
Masuma Parvin \\ Dept. of Natural sciences, Daffodil International University, Bangladesh
}

\begin{abstract}
This paper examines the effect of net migration on prospective population growth in Dhaka City for the next several years. The paper deals with the urban challenges in Bangladesh focusing on rapid urban growth in the megacity of Dhaka. Here Population of Dhaka city has been predicted with the help of an ordinary differential equation model known as Malthusian Exponential population model which is parameterized by growth rate. In order to include the immigrant population, we make necessary modification of the model, which is again an exponential model where the growth rate $(R)$ is the sum of the actual growth rate (a) and immigrant rate $(r)$.We use fourth order Runge-Kutta scheme for the numerical solution of the autonomous and non-autonomous case where we incorporate the growth rate as a function of time. We perform error estimation of the numerical solution which justifies the correctness of the implementation by using computer programming. The procedure used in this study is by comparing two projected population scenarios one with constant growth rate and the other is time dependent growth rate based on the latest data collected through surveys of population censuses and relevant studies.
\end{abstract}

Keywords: Exponential model, growth rate method, migration, population prediction, urban structure.

\section{Introduction}

The paper aims to explore the nature of urban growth in Dhaka City, Bangladesh using a mathematical model. It has highlighted the city of Dhaka as the urbanization of the whole country is interlinked with the intense development of the city. The rapid urbanization of the city since its emergence as the capital of an independent state is due mainly to massive migration of rural population.

The main purpose of the present paper is to highlight the recent trends in migration and urbanization in Dhaka city. According to The World Bank Office [7], Dhaka, June 2007, Dhaka is a highly dynamic city that attracts some 300,000-400,000 new migrants each year and Population projections indicate that Dhaka is expected to grow to about 20 million in 2020, making it the world's third largest city. The highly increasing trend in population of Dhaka is a great threat to the infrastructure of Dhaka. So, prediction of population of Dhaka is very essential to build up a planned Dhaka City. For this objective firstly we have predict the future population of Dhaka considering immigrant population.

Enrolment can be projected using either mathematical or analytical methods. In order to produce more accurate results in a more efficient way one should prefer mathematical model which can characterize the parameters like death rate, birth rate, fertility rate, immigration, living resources etc.

Now in this work we study the population prediction of Dhaka City based on a linear, autonomous exponential differential equation model which is known as Malthusian Population Model and parameterized by growth rate and Immigrant people per year. We have used the data collected from Bangladesh e-journal of sociology [3], Research paper on "urban poor in Dhaka" [12].In terms of immigrant people the Malthusian Population Model can be defined as:

$$
\begin{aligned}
\frac{d p}{d t} & =a p+I \ldots \ldots \ldots \\
\text { or, } \frac{1}{P} \frac{d p}{d t} & =a+\frac{1}{p}=R(t)
\end{aligned}
$$

Where (1) represents the growth rate and I represents immigrant of Dhaka per year. Here the calculations are based on parameters characterizing growth rate and immigrant people per year.

Firstly, we study the census survey report on Dhaka City (1981-2008) and observe that the population of Dhaka City had been increasing in an exponential manner. We therefore consider the Malthusian exponential model in order to project the population of Dhaka City for the next several decades. The model is a first order ordinary differential equation parameterized by the growth rate of the population. In order to include the immigrant population, we make necessary Modification of the model, which is again an exponential model where the growth rate $(R)$ is the sum of the actual growth rate $(a)$ and immigrant rate $(r)$.

The exists classical solution of the differential equation model as an IVP for both the time independent and time dependent growth rate i.e. for both autonomous and non-autonomous cases. However, for non- 
autonomous case, the calculation of the population from the exact solution is rather complicated due to the integration of the growth rate $R(t)$ which needs to incorporate from data.

We, therefore, prefer numerical method for the solution of the Ordinary Differential Equation model as an I.V.P. for time dependent growth rate. First we consider the autonomous case, where we choose the growth rate so that population trend agrees with that of the census data. Then with this growth rate we present the future projection for several decades both with exact and numerical solution method.

For the non-autonomous case, we model the growth rate $R(t)$ as an exponential function so that the growth rate trend agrees with that of the census (1981-2008).Then we incorporate this growth rate function in the numerical implementation of the non-autonomous exponential model by using fourth-order Runge-Kutta method. We perform error estimation of the numerical solution which justifies the correctness of the implementation by using computer programming. We present the predicted population for both autonomous and non-autonomous case.

\section{Growth Rate Method}

Arun.C Mehta [6] discussed various methods of projecting population (mathematical, economic and component methods).Some are very sophisticated and rigorous while others are simple and less sophisticated. Normally, population in future is governed by the following equation:

$\mathrm{P}_{\mathrm{n}=} \mathrm{P}_{0}+$ Number of Births $(\mathrm{B})-$ Number of Deaths $(\mathrm{D})+\operatorname{Net}$ Migration $\left(\mathrm{N}_{\mathrm{m}}\right)$

For the projection of population in $2011\left(\mathrm{P}_{\mathrm{n}}\right.$ ) base year population $\left(\mathrm{P}_{\mathrm{o}}\right)$ in 2001, the number of births and deaths between 2001 and 2011 and net migration is required. Keeping in view the in-migration and outmigration, net migration may be either positive or negative. Though population in the base year (2001) is available, number of births, deaths and migration in future needs to be projected which is not an easy task. Therefore, we have discussed simple and easy-to-handle methods of population projections given the purpose. We consider here the growth rate method.

For computing the annual rate of growth (simple), the following formula can be applied to the information at any two points of time

$$
\mathrm{r}=\frac{1}{\mathrm{n}} \frac{\left[\mathrm{p}_{\mathrm{n}}-\mathrm{p}_{0}\right]}{\mathrm{p}_{0}} \times 100
$$

Where, $r=$ annual rate of growth, $P_{n}=$ population in the current year

$\mathrm{P}_{\mathrm{o}}=$ population in the base year, $\mathrm{n}=$ number of intermediary years.

Let population of Dhaka be given as 34.40 million in the year $1981\left(\mathrm{P}_{\mathrm{o}}\right)$, as against 68.87 million in the year $1991\left(P_{n}\right)$, then 'r' would be,

$$
\mathrm{r}=\frac{1}{\mathrm{p}(1981)} \frac{\mathrm{p}(1991)-\mathrm{p}(1981)}{(10)} \times 100
$$

Here $r$ gives the decadal rate of growth which has taken place between the two given years, 1981 to 1991. By assuming that this rate of growth would continue in the future, population figures can be obtained in any given year. Thus, in this method, the net increment between two years is obtained by applying ' $r$ ' to the base year population which means the increment remains constant irrespective of the year, and, hence, considered as a crude method of projection. The same method can also be used for projecting other variables like enrolment. One of the limitations of this method is that while computing the rate of growth, it considers information at only two points of time. Thus, it fails to utilize the available statistics fully.

\section{Exponential Differential Equation Introducing Immigrant (I )}

First of all it seems to us impossible to model the growth of a species by a differential equation since the population of any species always changes by integer amounts. We know the population of any species can never be a differentiable function of time. If a given population is very large and suddenly increased by one, then the change is very small compared to the given population, thus we make the approximation that large population change continuous and even differentiable with time. We will discuss Malthusian model (Martin Braun [1]) and Exponential Differentiable Equation Population Model introducing the term Immigrant people based on "Exponential growth model". If the population of a given species is $p_{0}$ at time $t_{0}$, and then $p(t)$ satisfies the initial value problem (IVP)

$$
\frac{d p}{d t}=\operatorname{ap}(t) \quad \text { And } \quad p\left(t_{0}\right)=p_{0}
$$

Here we discuss about exponential model (Malthus's Model) with introducing immigrant. Exponential model was developed by Thomas Robert Malthus (1766-1834). Any species satisfying the Malthusian law of population growth grows exponentially with time. The exponential differential equation (Malthusian population model) can be written by the following linear differential equation: 


$$
\frac{\mathrm{dp}}{\mathrm{dt}}=\mathrm{ap} \ldots \ldots \ldots \ldots \ldots \ldots \ldots \ldots \ldots . . . . \quad \text { (8) } \therefore \quad \mathrm{a}=\frac{1}{\mathrm{p}} \frac{\mathrm{dp}}{\mathrm{dt}}
$$

Here, $\mathrm{a}$ is called the specific growth rate, where $\mathrm{a}=$ constant

If we consider the immigrant people of Dhaka city per year as I and introduce it into the equation (8) then the dynamics of the population is described by the differential equation: $\frac{\mathrm{dp}}{\mathrm{dt}}=\mathrm{ap}+\mathrm{I} \ldots \ldots \ldots \ldots \ldots$

Where I = Immigrant per year

$$
\begin{gathered}
\text { which has the following solution: } p(t)=p_{0} e^{\left(a+\frac{I}{p}\right)\left(t-t_{0}\right)} \\
\text { Where } I=r p
\end{gathered}
$$

Exponential Model combines one ecological process reproduction and one parameter immigrant population (I) .Both of these depends on population number (or density). The rate of both processes corresponds to the mass-action law with coefficients: $\mathrm{a}_{0}$ for reproduction and $\mathrm{I}=\mathrm{rp}$ for immigrant population.

\subsection{Exact Solution of Malthus's Model}

From Equation (4) we have, $\frac{1}{p} \frac{d p}{d t}=a \Rightarrow \int \frac{d p}{p}=\int a d t \Rightarrow \ln |p|=a t+c$, where $\mathrm{c}$ is integrating constant. $|p|=e^{a t+c} \Rightarrow p=A e^{a t} \quad \ldots \quad \ldots \quad \ldots \quad$ (5)

Using the initial condition $p\left(t_{0}\right)=p_{0}$ we get,$p_{0}=A e^{a t} \therefore A=p_{0} e^{-a t_{0}}$

Now substituting the value of $A$ in (5), we have $p(t)=p_{0} e^{-a t_{0}} e^{a t}=p_{0} e^{a\left(t-t_{0}\right)}$

The solution of the Initial Value problem is $\frac{d p}{d t}=a p$ where $p\left(t_{0}\right)=p_{0}$

$$
p(t)==p_{0} e^{a\left(t-t_{0}\right)} \quad \ldots \quad \ldots \quad \ldots(6)
$$

Hence any species satisfying the Malthusian Law of population growth exponentially with time $t$.

Proposition: Now we have just formulated a very simply model for population growth; so simple, in fact that we have been able to solve it completely a few items. It is important, therefore, to see if this model, with its simplicity, has any relationship at all with reality. Let $p(t)$ denotes the human population of Dhaka City at time $t$. It has estimated that the Dhaka City's population in 1981 was 3440147, in 2001 was 10912206 and in the year 1981 the population was increasing at a rate $7.53 \%$ per year. Thus, $t_{0}=1981, p_{0}=3.44 \times 10^{6}$ and $a=0.0753$, so that $P(t)=\left(3.44 \times 10^{6}\right) e^{0.0753(t-1981)}$

Now, we can certainly check this formula out as far as past populations. It reflects with surprising accuracy the population estimate for the period (1901-2001). The population of Dhaka City has been doubling about every 10 years (1981-1991) and our equation predicts a doubling of Dhaka City's population 19.2051 years. To prove this, we observe that the population of Dhaka City doubles in a time, $T=t-t_{0}$

Where $e^{0.0753 T}=2$

Taking logarithms of both sides of this equation we get, $\quad \log _{\mathrm{e}}{ }^{0.0753 \mathrm{~T}}=\ln 2$

$$
\Rightarrow 0.0753 \mathrm{~T}=\ln 2 \Rightarrow \mathrm{T}=\frac{0.0753}{\ln 2}=9.205141 \approx 10
$$

To prove this, we observe that the population of Dhaka City triples in a time $T=t-t_{0}$ where $\mathrm{e}^{0.0753 \mathrm{~T}}=3$. Taking logarithms on both sides of this equation, we get $\log _{\mathrm{e}} \mathrm{e}^{0.0753 \mathrm{~T}}=\ln 3 \Rightarrow 0.0753 \mathrm{~T}=\ln 3 \Rightarrow \mathrm{T}=\frac{\ln 3}{0.0753}=\frac{1.109816}{0.0753}=14.7358 \neq 20$

Therefore it would seem that this model is unreasonable and should be thrown out. However, we cannot ignore the fact it offers exponential agreement in the past. Now, we have additional evidence that populations do grow exponentially. Let us suppose that the Microtus Arvallis Pall, a small rodent which represents very rapidly. We consider the unit time to be a month and assume that the population is increasing at rate $40 \%$ per month. If there are two rodents present initially at time $t=0$, then $p(t)$, the number of rodents at time $t$, satisfies the initial-value problem

Consequently, $\mathrm{p}(\mathrm{t})=\mathrm{p}(0) \mathrm{e}^{\mathrm{at}}=\mathrm{p}_{0} \mathrm{e}^{\mathrm{at}}=2 \mathrm{e}^{0.4 \mathrm{t}}$

$$
\frac{\mathrm{dp}}{\mathrm{dt}}=0.4 \mathrm{p} \Rightarrow \frac{1}{\mathrm{p}} \frac{\mathrm{dp}}{\mathrm{dt}}=0.4 \Rightarrow \mathrm{a}=0.4 \text { and } \mathrm{p}(0)=2 \Rightarrow \mathrm{p}_{0}=2
$$

Table 1 compares the observed population with the population calculated from equation (7). 
Table 1: The growth of Microtus Aravallis pall

\begin{tabular}{|l|l|l|l|l|l|l|}
\hline Months & 0 & 2 & 4 & 6 & 8 & 10 \\
\hline$P$ observed & 2 & 5 & 10 & 20 & 50 & 109 \\
\hline$P$ calculated & 2 & 4.45 & 9.90 & 22.04 & 49.06 & 109.19 \\
\hline
\end{tabular}

As one can see, there is excellent agreement.

\subsection{Calculation Of Growth Rate Of Populationa(T) And Immigrant Rate R(T)}

We know that, in case of Malthusian Model (Exponential Model) the growth rate of population a is constant i.e. a is not a function of time and this model is applicable for small period of time. In case of Dhaka City we assume that both $a$ and $\mathrm{r}$ are function of time $(\mathrm{t})$.But we have already observed that the population growth of Dhaka City shows the exponential trend. So, in this paper we have applied the Malthusian Model to predict the future population growth of Dhaka City which is always agree with the exponential trend. In previous section we have discussed the analytical solution of the exponential differential equation as $\mathrm{p}(\mathrm{t})=\mathrm{p}_{0} \mathrm{e}^{(\mathrm{a}+\mathrm{r})\left(\mathrm{t}-\mathrm{t}_{0}\right)}$

Let $\mathrm{p}_{0}=$ population at timet $=\mathrm{t}_{0}, \quad \mathrm{p}(\mathrm{t})=$ Population at time tand also let, $\mathrm{t}-\mathrm{t}_{0}=\mathrm{T}$ then from equation (11), we have

$$
p(t)=p_{0} e^{(a+r) T}
$$

Again, let $[a(t)+r(t)]=$ Relative growth rate $=R(t)$

Where $\quad a(t)=\frac{1}{p} \frac{d p}{d t}=$ growth rate of population with respect to birth and death

$$
\begin{aligned}
& r(t)=\text { immigrant rate } \\
& p(t)=p_{0} e^{R(t) T}
\end{aligned}
$$

Then (12) gives,

Using (11), (12) \& (13) we can calculate at first the relative growth rate $R(t)$, then $p(t)$.

\subsection{Solution of Malthusian Population Model}

Now, Malthusian Model in terms of immigrant people we have from (9)

$$
\begin{gathered}
\frac{d p}{d t}=a p+I \text { or, } \frac{d p}{a p+I}=d t \text { or, } \int \frac{d p}{a p+I}=\int d t \\
\text { or, } \frac{1}{a} \log _{\mathrm{e}^{(I+a p)}}=t+c ; \quad[c=\text { integratingconstant }] \text { or, } \log _{\mathrm{e}^{(I+a p)}}=a(t+c) \\
\text { or, }(I+a p)=\mathrm{e}^{\mathrm{a}^{(t+c)}} \text { or, } p(t)=\frac{\mathrm{e}^{\mathrm{a}(\mathrm{t}+\mathrm{c})}-\mathrm{I}}{\mathrm{a}}
\end{gathered}
$$

Researchers believe that migration contributes to at least $40 \%$ of Dhaka's population.

Then $\mathrm{I}=\frac{40}{100} \mathrm{p} \Rightarrow \mathrm{I}=0.4 \mathrm{p}$. Then equation (10) becomes $\frac{\mathrm{dp}}{\mathrm{dt}}=\mathrm{ap}+0.4 \mathrm{p}$

$$
\begin{gathered}
\Rightarrow \frac{1}{\mathrm{p}} \frac{\mathrm{dp}}{\mathrm{dt}}=(\mathrm{a}+0.4) \Rightarrow \log _{\mathrm{e}^{\mathrm{p}}}=\mathrm{at}+0.4 \mathrm{t}+\mathrm{c} \Rightarrow \mathrm{p}(\mathrm{t})=\mathrm{e}^{\mathrm{at}+0.4 \mathrm{t}+\mathrm{c}} \\
\Rightarrow \mathrm{p}(\mathrm{t})=\mathrm{e}^{\mathrm{at}} \cdot \mathrm{e}^{0.4 \mathrm{t}} \cdot \mathrm{e}^{\mathrm{c}} \Rightarrow \mathrm{p}(\mathrm{t})=\mathrm{Ae}^{(\mathrm{a}+0.4) \mathrm{t}}
\end{gathered}
$$

When $\mathrm{t}=\mathrm{t}_{0}$ then $\mathrm{p}\left(\mathrm{t}_{0}\right)=\mathrm{p}_{0}$ using by initial condition we get $\mathrm{p}_{0}=\mathrm{Ae}^{(\mathrm{a}+0.4) \mathrm{t}_{0}}$

$\therefore \mathrm{A}=\mathrm{p}_{0} \mathrm{e}^{-(\mathrm{a}+0.4) \mathrm{t}_{0}}$ So, $\mathrm{p}(\mathrm{t})=\mathrm{p}_{0} \mathrm{e}^{-(\mathrm{a}+0.4) \mathrm{t}_{0}} \mathrm{e}^{(\mathrm{a}+0.4) \mathrm{t}}=\mathrm{p}_{0} \mathrm{e}^{(\mathrm{a}+0.4)\left(\mathrm{t}-\mathrm{t}_{0}\right)}$

So, we have, $\quad \mathrm{p}(\mathrm{t})=\mathrm{p}_{0} \mathrm{e}^{(\mathrm{a}+\mathrm{I})\left(\mathrm{t}-\mathrm{t}_{0}\right)}$

This is the required solution of Malthusian population in terms of immigrant people of Dhaka city.

\section{Numerical Simulation}

By using the data of Bangladesh e-journal of sociology [3], we have drawn the Fig 1and Fig 2. From the figure we see that the population gradually increases as an exponential manner with respect to the actual Dhaka city census data from 1901 through 2001.

We see that, the growth rate of Dhaka City is decreasing (Fig 3) but due to the Immigrant rate the total population of Dhaka city is increasing. The population of the city reached to 12.7 million in 2008 and the Crude growth rate has 12.95 per thousand Populations in 2008, which is very high. In the Fig 3 we have shown the population growth rate of Dhaka city in the year 1981, 1991 and 2001 which is $0.1293,0.1002$ and 0.0584 respectively from our calculation. The level of urban population growth of Dhaka City was extremely low in 1951 with only $1.28 \%$ of the total population living in urban areas. It has increased gradually to $5.74 \%$ in 1961 and then very rapidly to $8.47 \%$ in 1974 but has started to decrease $7.53 \%$ in $1981,6.55 \%$ in 1991 and $4.33 \%$ in 2001 (BBS, 1997 and BBS, 2001) [4].Though the growth rate in population of Dhaka city has been decreasing, its overall population has been increasing and it would continue to increase until zero growth rate is attained. The city will have the largest population when the growth rate us zero. The population of the city is 
increasing very rapidly due mainly to rural-urban migration. Now we use a Matlab program to predict the future population growth rate of Dhaka City from the year 1981 to 2021 by numerical solution. Here we use the exponential Model for the prediction. Also we use Matlab Program to compare between the Specific Growth Rate and the Immigrant growth rate of the Dhaka City for the year 2001 to 2031( Fig 5).

The figure below shows the graph of the solution of the exponential growth model for the Dhaka City.

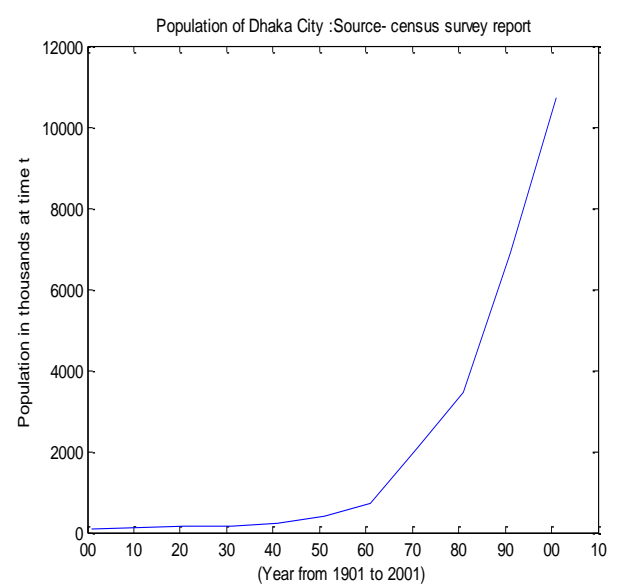

Figure 1: Population of Dhaka City (1901-2001)

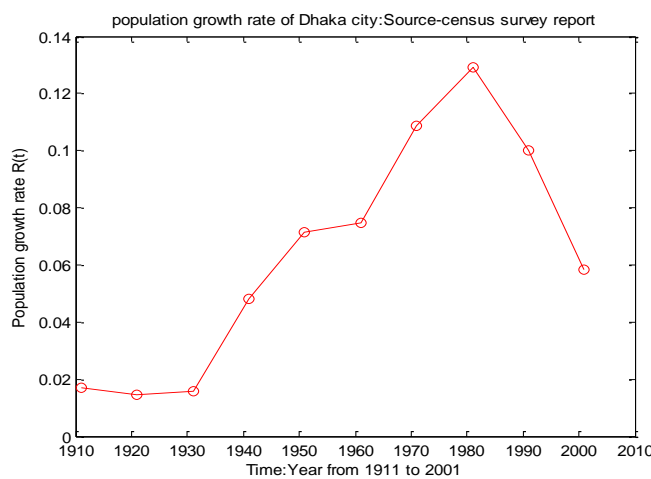

Figure 3: Population Growth rate of Dhaka City According to Census Survey Report

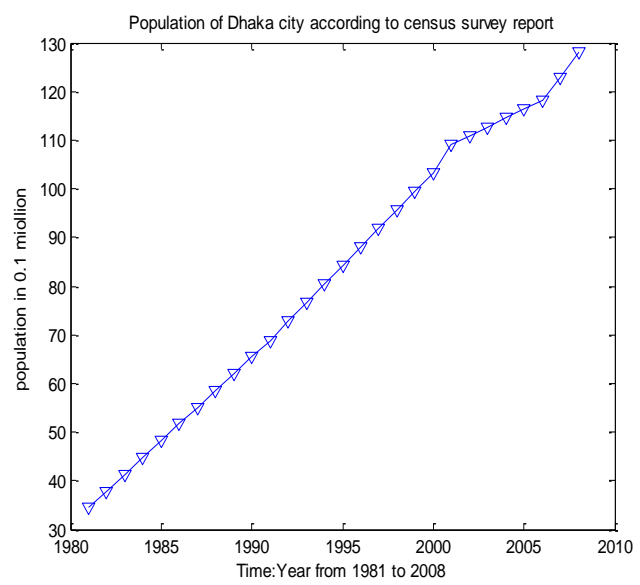

Figure 2: Population of Dhaka (1981-2008) according to Census Survey Report

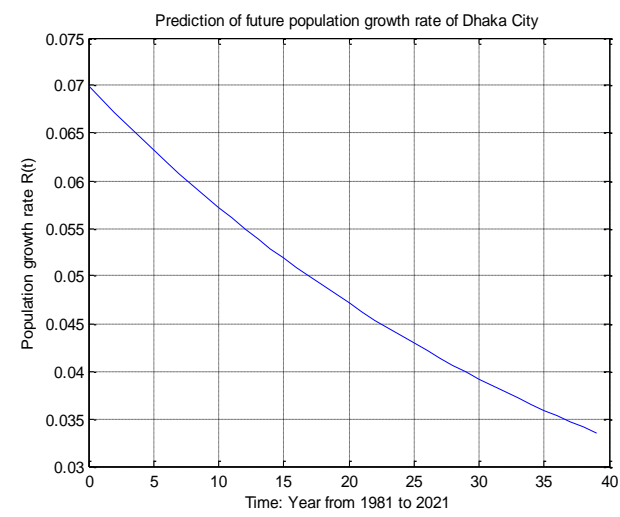

Figure 4: Prediction of future population growth rate of Dhaka City by numerical solution

\subsection{Fitting An Exponential Model To Data}

As we have seen the actual Dhaka City census data from 1901 through 2001produces an exponential curve, we therefore use the Malthusian exponential model $\frac{\mathrm{dp}}{\mathrm{dt}}=\mathrm{ap}, \mathrm{p}\left(\mathrm{t}_{0}\right)=\mathrm{p}_{0}$

Our test case will be the Dhaka City census data, first up to 1991, then up to 2001. To determine whether a given set of data can be modeled by the exponential differential equation we have to estimate values of the derivative $\frac{1}{\mathrm{p}} \frac{\mathrm{dp}}{\mathrm{dt}}$ from the data. We will do that by symmetric differences. The slope $\frac{1}{\mathrm{p}} \frac{\mathrm{dp}}{\mathrm{dt}}$ at a given census year $t$ is approximated by the slope of the line joining the points 10 years earlier and 10 years later. For example,

$$
\begin{aligned}
& \text { the growth rate } \frac{1}{\mathrm{p}} \frac{\mathrm{dp}}{\mathrm{dt}} \text { in } 1991 \text { is approximately } \\
& \left.\frac{1}{\mathrm{p}(1981)} \frac{\mathrm{p}(1991)-\mathrm{p}(1981)}{(1991-1981)} \ldots \ldots \ldots \ldots \ldots \ldots \ldots \ldots \ldots \text { (14 }\right)
\end{aligned}
$$

We may rewrite the exponential equation in the form

$$
\frac{1}{\mathrm{p}} \frac{\Delta \mathrm{p}}{\Delta \mathrm{t}}=(\mathrm{a}+\mathrm{r})=\mathrm{R}(\mathrm{t})
$$

Where $\quad \frac{1}{\mathrm{p}} \frac{\Delta \mathrm{p}}{\Delta \mathrm{t}}=\mathrm{R}(\mathrm{t})$ is the relatively growth rate of the population of Dhaka City. 


\subsection{Future Population Projection of Dhaka City by Numerical Simulation}

Our Exponential model is: $\quad \frac{\mathrm{dp}}{\mathrm{dt}}=\mathrm{ap}+\mathrm{I} \ldots \ldots \ldots \ldots \ldots$ (16)

Where I is assumed to be Immigrant population of Dhaka City which is determined by the following formula

$$
\mathrm{I}=\operatorname{rp} \ldots \ldots \ldots \ldots \ldots \ldots \ldots(17)
$$

We can solve (16) and (17) as follows . $\frac{1}{\mathrm{p}} \frac{\mathrm{dp}}{\mathrm{dt}}=\mathrm{a}(\mathrm{t})+\mathrm{r}(\mathrm{t})=\mathrm{R}(\mathrm{t}) \ldots \quad \ldots \quad \ldots$ (18)

So, we have $a(t)=R(t)-r(t) \quad \ldots \quad \ldots \quad$ (19)

Wherea $(\mathrm{t})>r(\mathrm{t}),(\mathrm{r}$ is the immigrantrate) .To estimate $\mathrm{a}(\mathrm{t})$, we model $\mathrm{R}(\mathrm{t})$ with an exponential equation in time. $\mathrm{R}(\mathrm{t})=\mathrm{R}_{0} \mathrm{e}^{\mathrm{mt}}$

Where $m=(R(2001)-R(1981)) / 20$ is determined by the given data [9] and $R_{0}$ is assumed to be initial growth rate (growth rate of the starting year 1981).

We introduce a Matlab program for comparing the population of Dhaka City between exact solution, numerical solution of the exponential model and the data of census survey (Fig 6). We perform an error estimation of the numerical solution which justifies the correctness of the implementation by using computer programming (Table1). From the Fig 6 we see that the population curves from census survey and the exponential model match at first in the starting year 1981, then continuing the matching. The two curves show some difference from the year 1985 to 1999.After that they again match in the year 2000 and continuing the matching up to 2001.

We also see that from the year 1981 to 2001(Fig 6), the numerical solution and exact solution of exponential model matches approximately all the time and shows a very little difference which can be negligible. So, we can say that the population growth of Dhaka City always supports the exponential model and we can use this model to predict the future population growth of Dhaka City.

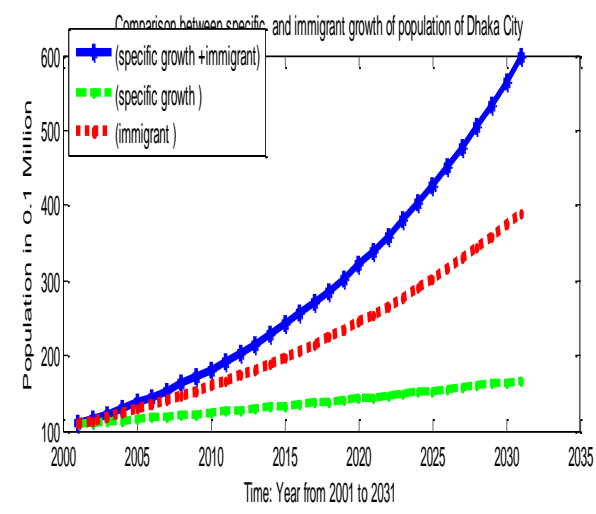

Figure 5: Comparison between specific and immigrant growth rate of Dhaka City.

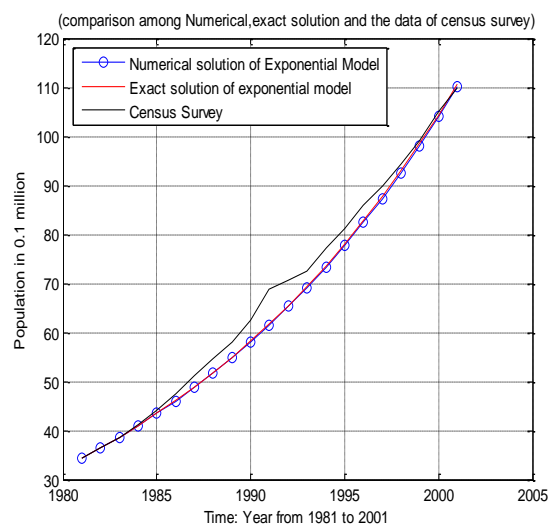

Figure 6: Comparison of Population for the Year 1981 to 2001 .

Table 2: Population of Dhaka City (in 0.1 million) from the Year 1981 to 2001.

\begin{tabular}{|c|l|l|l|l|}
\hline Year & $\begin{array}{l}\text { Actual } \\
\begin{array}{l}\text { Populat } \\
\text { ion } \\
\text { from } \\
\text { census }\end{array}\end{array}$ & $\begin{array}{l}\text { Exact } \\
\text { solution } \\
\text { of } \\
\text { Populati } \\
\text { on }\end{array}$ & $\begin{array}{l}\text { Numeri } \\
\text { cal } \\
\text { Solutio } \\
\text { n Of } \\
\text { populati } \\
\text { on }\end{array}$ & Error \\
\hline 1981 & 34.400 & 34.4015 & 34.400 & 0.0000 \\
\hline 1982 & 36.440 & 36.4722 & 36.462 & 0.0003 \\
\hline 1983 & 38.500 & 38.6675 & 38.6483 & 0.0005 \\
\hline 1984 & 41.2400 & 40.9950 & 40.9653 & 0.0007 \\
\hline 1985 & 44.1900 & 43.4625 & 43.4212 & 0.0010 \\
\hline 1986 & 47.6300 & 46.0786 & 46.0244 & 0.0012 \\
\hline 1987 & 51.0800 & 48.8522 & 48.7836 & 0.0014 \\
\hline 1988 & 54.5300 & 51.7927 & 51.7082 & 0.0016 \\
\hline 1989 & 57.9800 & 54.9102 & 54.8082 & 0.0019 \\
\hline 1990 & 62.4200 & 58.2154 & 58.0940 & 0.0021 \\
\hline 1991 & 68.8700 & 61.7195 & 61.5768 & 0.0023 \\
\hline 1992 & 70.6900 & 65.4345 & 65.2684 & 0.0025 \\
\hline 1993 & 72.5200 & 69.3731 & 69.1813 & 0.0028 \\
\hline 1994 & 77.3400 & 73.5488 & 73.3288 & 0.0030 \\
\hline
\end{tabular}




\begin{tabular}{|l|l|l|l|l|}
\hline 1995 & 81.1700 & 77.9759 & 77.7250 & 0.0032 \\
\hline 1996 & 85.9900 & 82.6694 & 82.3847 & 0.0034 \\
\hline 1997 & 89.8200 & 87.6454 & 87.3238 & 0.0037 \\
\hline 1998 & 94.2400 & 92.9210 & 92.5589 & 0.0039 \\
\hline 1999 & 99.1500 & 98.5141 & 98.1079 & 0.0041 \\
\hline 2000 & 105.010 & 104.4438 & 103.989 & 0.0043 \\
\hline 2001 & 109.990 & 110.7305 & 110.223 & 0.0045 \\
\hline 2002 & 110.9 & 110.18 & 125.65 & 0.1405 \\
\hline 2003 & 112.7 & 116.46 & 133.65 & 0.1476 \\
\hline 2004 & 114.5 & 123.09 & 142.15 & 0.1548 \\
\hline 2005 & 116.3 & 130.11 & 151.20 & 0.1621 \\
\hline 2006 & 118.1 & 137.53 & 160.82 & 0.1694 \\
\hline 2007 & 122.9 & 145.36 & 171.06 & 0.1767 \\
\hline 2008 & 127.9 & 153.65 & 181.94 & 0.1841 \\
\hline
\end{tabular}

The 2001 Census of Bangladesh found the population of Dhaka Statistical Metropolitan Area (DSMA) or Dhaka Megacity Region to be 9.923 million, within its $1325 \mathrm{sq} \mathrm{km} \mathrm{limits.} \mathrm{DSMA,} \mathrm{however,} \mathrm{is} \mathrm{an} \mathrm{extended}$ metropolitan region, comprising the mother city Dhaka or the Dhaka City Corporation (DCC) area and six other medium and small municipalities/towns and vast expanses of rural entities in between the urban centers. DCC has an area of only $360 \mathrm{sq} . \mathrm{kms}$ and had a population of 5.9 million in 2001.Using the data of B.B.S [4], we have drawn the figure 7 and 8.In the figure 8, we find that the graph is S-shaped i.e. population of Dhaka City according to Area obey logistical population model.i.e. Logistical population model can be applied on the population of Dhaka City considering the area.

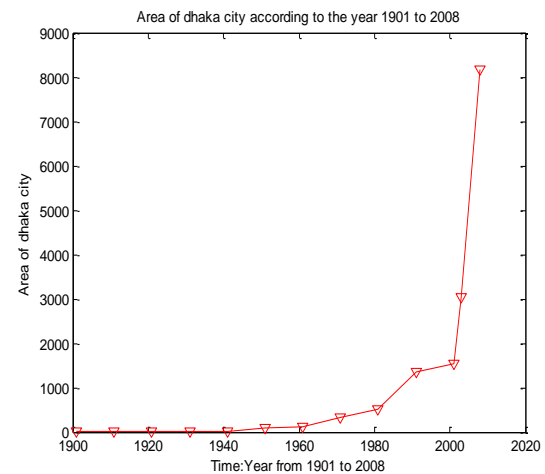

Figure 7: Increasing area of Dhaka city (1901 to 2008)

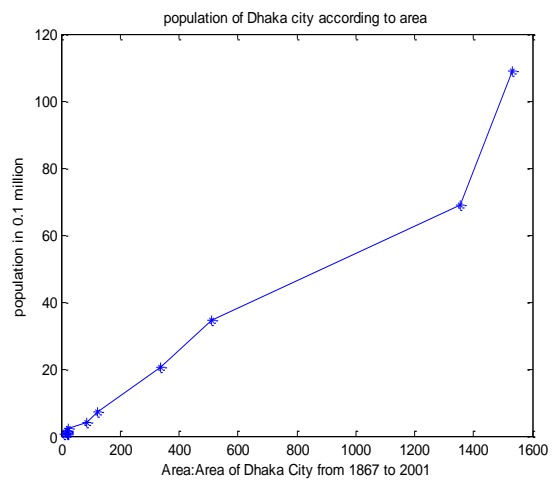

Figure 8: Population of Dhaka city according to area from 1867 to 2001 .

Fig 9 shows the exponential curve (1981-2021) together with the actual Dhaka City census data(19812001). We observe that from the starting year 1981, according to census survey report, the population of Dhaka has been increased more than the exponential rate. The two curve of population matches at last in the year 2001.So, this is the matching point and by considering the population growth rate of this point or year, we extend the exponential curve and predict the future population of Dhaka for the 20 years (2001-2021) considering constant growth rate.

Fig 9 shows the trend of population growth of Dhaka City for the future two decades(2001-2021) based on the previous two decades census survey data of Dhaka City(1981-2001).We observe that in the first two decades ( 1981 to 1991 and 1991 to 2001) population of Dhaka has been increased by 2.64 million ( 1981 1991) and 4.67 million (1991-2001). We have plot these data in the exponential model and with the help of numerical solution we predict that after the future two decades (2001 to 2011 and 2011 to 2021) .the population of Dhaka will be increased by 8.26 million (2001-2011) and 14.61 million (2011-2021).We observe that in the decade (2011-2021) the population of Dhaka will increase 6.35 million more from the decade (2001-2011). We observe the highest population growth of Dhaka City in the decade (2011-2021), average 1.46 million per year (approximately).So, we can say that the growth rate of Dhaka City's population will be continue the exponential trend and we can project the future population of Dhaka City by also numerical solution where the population growth rate is a time dependent function.

Up till now, we have discussed about constant growth rate (time independent growth rate) of population. By using this constant growth rate we have predicted the future population of Dhaka City from 1981 to 2021.Now, we will discuss about the time dependent growth rate.

By using the time dependent growth rate, at first, we will predict the future population growth rate of Dhaka City by numerical solution. Then, using that growth rate we can predict the future population of Dhaka 
City. Now, we develop a Matlab Program for predicting the future population growth rate of Dhaka City by numerical solution. Here is a figure and data obtained by Numerical Solution of Population projection for the time dependent growth rate (Fig-10 and Table 3)

We find that the trend of population growth of Dhaka City for the future two decades (2001-2026) based on the previous two decades' census survey data of Dhaka City (1981-2001) (Fig 10).We observe that in the first two decades (1981 to 1991 and 1991 to 2001) population of Dhaka has been increased by 3.06 million (1981-1991) and 4.46 million (1991-2001). We have plot these data in the exponential model and predict that after the future two decades (2001 to 2011 and 2011 to 2021) the population of Dhaka will be increased by 4.24 million (2001-2011) and 5.67 million (2011-2021). We observe that in the decade (2011-2021) the population of Dhaka will increase 1.43 million more from the decade (2001-2011).So, we can say that the growth rate of Dhaka City's population will be continue the exponential trend. We observe the highest population growth of Dhaka City in the decade (2011-2021), average 0.736 million per year (approximately).In the last decade, 15 luc people added to the Dhaka city population. Currently the capital city's population stands at $1.6 \mathrm{crore}$. By 2025 , the United Nations forecasts that Dhaka will reach 23 million. We have seen from the data obtained by numerical solution that Dhaka's population will be 23 million by 2025. Mohammad A.Mabud.Phd, in a Seminar on Bangladesh Population Prospects and Problems at North South University, Dhaka [9] in 2008, estimated the present population is about 11 million and growth rate is $5 \%$, it will be doubling after 14 years, therefore by the 2022 the population will be 22 million.

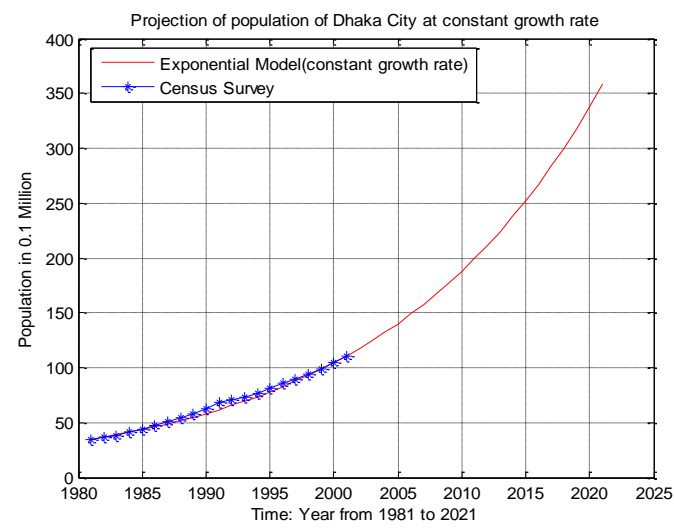

Figure 9 : Comparing two scenarios of census survey report and projecting population of Dhaka city.

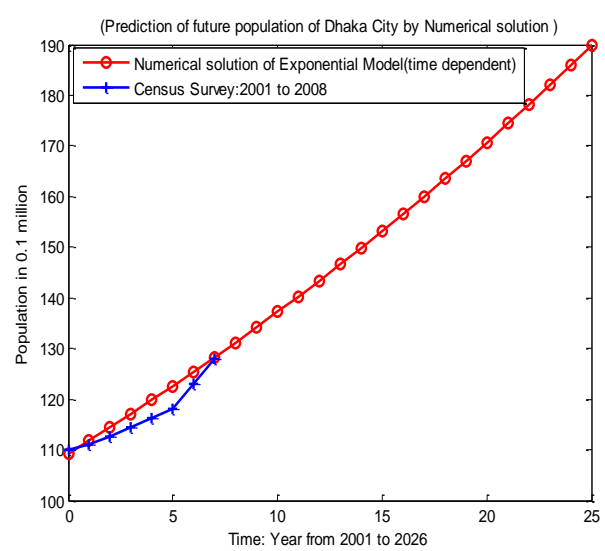

Figure 10: Projection of Urban Population of Dhaka City at time dependent Growth rate by numerical solution.

Table 3: Urban Population of Dhaka city (in Millions) from 2001 to 2026

\begin{tabular}{|l|l|l|l|}
\hline Year & population & year & population \\
\hline 2001 & 10.912 & 2014 & 16.688 \\
\hline 2002 & 11.283 & 2015 & 17.230 \\
\hline 2003 & 11.665 & 2016 & 17.787 \\
\hline 2004 & 12.058 & 2017 & 18.361 \\
\hline 2005 & 12.463 & 2018 & 18.953 \\
\hline 2006 & 12.880 & 2019 & 19.561 \\
\hline 2007 & 13.309 & 2020 & 20.188 \\
\hline 2008 & 13.750 & 2021 & 20.834 \\
\hline 2009 & 14.205 & 2022 & 21.499 \\
\hline 2010 & 14.673 & 2023 & 22.183 \\
\hline 2011 & 15.155 & 2024 & 22.888 \\
\hline 2012 & 15.651 & 2025 & 23.614 \\
\hline 2013 & 16.162 & 2026 & 24.362 \\
\hline
\end{tabular}

\section{Conclusion}

In this study a mathematical analysis of the future population of Dhaka City is carried out based on an ordinary differential equation model which is called Exponential Differential Equation Model (Malthusian Population Model) in terms of immigrant population. In this model at first the growth rate $a$ and consequently the immigrant rate $r$ are assumed to be constant and a formula is developed to calculate the relatively growth rate $\mathrm{R}$ which is also constant. However, considering growth rate $a$ as exponential equation we have also shown how to calculate $R(t)$ as a function of $t$ from the data and some Matlab Programs are used for this purpose. Also, Matlab programs are developed for the direct projection of future population of Dhaka City. First we test our program to implement the numerical scheme for the population of Dhaka City (1901-2001) and we find our 
projection has a very good quantitative and qualitative $(\mathrm{J}$ - shaped) agreement with the actual data. Then we use this program to project future population of Dhaka City by using Growth Rate Method. Here, we predict the future population from 2001 to 2026 by numerical solution and this result shows a very good agreement with the results due to Census Survey Report [4].According to the report of World Bank 2007[7]; UN-DESA 2011, Dhaka's population projected to grow to 17 million by 2015 and we observed that our population will be approximate to 17.23 million in the year 2015 and then it will attain24.36 million in the year 2026. The population gradually increases as an exponential manner which shows a good qualitative agreement with the results of [4].

\section{References}

[1] M. Braun, Differential Equation and their Application ( $4^{\text {th }}$ ed. Narosha Publishing House, 1993).

[2] N. Hasan, Population Projection in Dhaka City Based on Malthusian Model, M.Sc. Thesis, Dept. of Mathematics, Jahangirnagar University, 2008.

[3] S.Hossain, Rapid Urban Growth and Poverty in Dhaka city, Bangladesh e-journal of sociology, 5(1), 2008, 57-80.

[4] B.B.S. (2007), Population Census - 2001(Community Series, Zilla: Dhaka), Bangladesh Bureau of Statistics, Planning Division, Ministry of Planning, Government of Bangladesh.

[5] C.M. Arun, Projections of Population, Enrolment and Teachers: Module on enrolment and population projections, Fellow, ORSM Unit, National Institute of Educational Planning and Administration, 17-B, January 182004

[6] Walter, W., Ordinary Differential Equation (Springer., 305-309, 1998).

[7] Dhaka: Improving Living Conditions for the Urban Poor, Bangladesh Development Series, Paper No. 17, The World Bank Office, Dhaka, June 2007.

[8] N. Islam, Dhaka city: Some general Concerns, Centre for Urban Studies, Dhaka. 3(6), 1999, 71-82.

[9] M. A. Mabud, Bangladesh's Population Projection, 2001-2101, Organization for Population and Poverty Alleviation (OPPA), Dhaka, 2008

[10] S.A. Sinthia, Sustainable Urban Development of Slum Prone Area of Dhaka City, World Academy of Science, Engineering and Technology, 2013,75.

[11] United Nations Department of Economic and Social Affairs, Population Division, and World Urbanization Prospects: The 2007 Revision, February, 2008.

[12] N. Islam and A. Shafi .Salma, Solid waste management and the urban poor in Dhaka, Research paper, Forum on Urban Infrastructure and Public Service Delivery for the Urban Poor Regional Focus: Asia, 2004. 